\title{
Escola que Protege - UMA CONTRIBUiçÃo À \\ REDE DE PROTEÇÃO SOCIAL
}

\section{Project "Escola que Protege" - A contribution to the social protection network}

\author{
Rosana Morgado*
}

\begin{abstract}
RESUMO
O presente artigo apresenta e analisa a experiência de realização do Projeto Escola que Protege no estado do Rio de Janeiro, destacando elementos sobre a construção/consolidação da rede de proteção social, particularmente nos campos da educação e assistência.
\end{abstract}

Palavras-chave: violência; garantia de direitos; rede de proteção social.

\begin{abstract}
Experience that took place in Rio de Janeiro, focused on the construction/consolidation of the social network, mainly about the education and welfare system.
\end{abstract}

Keywords: violence; social rights; social network.

\section{RESUMEN}

El presente texto presenta y analisa la experiencia de um Proyecto socio-educativo: "Escola que Protege", en la provincia de Rio de Janeiro (Brasil), destacando los elementos acerca de la construcción/consolidación de la red de protección social, en especial la articulación entre los sectores de educación y asistencia social.

Palabras-clave: violencia; derecho social; protección social.

Apresentação

\section{O Projeto de Extensão Escola que}

Protege, em sua fase presencial, teve início no estado do Rio de Janeiro em agosto de 2006, através de um convênio do Ministério da Educação/Secretaria de Educação Continuada, Alfabetização e Diversidade - SECAD -, realizado com a UFRJ através da PR5, na pessoa da Pró-Reitora Extensão: Profa ${ }^{a}$ Laura Tavares, da Superintendente Acadêmica de Extensão: Prof ${ }^{a}$. Ana Inês Sousa e sob minha coordenação pedagógica.

No estado do Rio de Janeiro foram selecionados 18 municípios, tendo como critério aqueles nos quais já estava implantado o Programa Escola Aberta ${ }^{1}$. Estão articulados

\footnotetext{
Professora da Escola de Serviço Social da UFRJ, Doutora em Sociologia.

1 O Programa Escola Aberta "busca contribuir para a construção da cidadania consciente, responsável e participante, favorecendo a inclusão sociocultural (particularmente do jovem estudante da educação básica das escolas públicas), a diminuição da violência e da vulnerabilidade socioeconômica e, por extensão, a promoção da paz e da melhoria da qualidade de vida da população. Pretende, ainda, transformar a escola em um ambiente mais atuante e presente na vida dos jovens e suas comunidades, promovendo maior diálogo, cooperação e participação entre os alunos, pais e equipes de profissionais que atuam nas escolas, além de contribuir para a complementação de renda das famílias".
} 
também a este Programa os Projetos: Conexões de Saberes, do Centro de Teatro do Oprimido - CTO-Rio e do Ministério do Esporte.

\section{Justificativa $^{2}$}

AConstituição de 1988, particularmente em seu art. 227, e o Estatuto da Criança e do Adolescente - ECA, promulgado em 1990, redefinem as responsabilidades da família, da sociedade e do Estado, visando a garantia da proteção integral, eixo em torno do qual se organiza o novo modelo legislativo. Crianças e adolescentes passam a ser legalmente considerados como sujeitos de direitos, em condição peculiar de desenvolvimento. A eles é assegurado um conjunto de direitos, a ser implementado por intermédio de políticas públicas que estabeleçam ações a cargo de agentes determinados.

A mudança do termo, de menor para crianças e adolescentes, supera a dimensão de uma mudança de terminologia, trazendo avanços para o enfrentamento da problemática. O termo menor, oriundo do campo jurídico, sempre foi utilizado de forma estigmatizante: menor carente, menor infrator, menor delinqüente, dentre outros. Contudo, verifica-se que ainda hoje algumas antigas práticas sociais são reeditadas, mesmo quando se utilizam da nova terminologia.

Foi ao longo da década de oitenta que, no Brasil, as denúncias de violação de direitos infanto-juvenis puderam ser realizadas. Isto foi possível a partir do processo de redemocratização da sociedade e da organização de diferentes movimentos sociais em torno de eixos comuns, como o da demanda pela estruturação de políticas públicas que enfrentassem as desigualdades sociais.
Embora o termo tenha sido substituído, significando que a infância e juventude brasileiras passam a ser consideradas como sujeitos de direitos, encontramos - ainda hoje - práticas profissionais que se pautam nos mesmos antigos valores. De fato, as inúmeras avaliações sobre a implantação do novo modelo trazem indicadores irrefutáveis acerca das violações dos direitos, ou das omissões na sua implantação, mostrando assim que não basta formular políticas coerentes com os propósitos do ECA: é preciso capacitar os agentes encarregados de sua execução, de modo a levar o direito da lei ao cotidiano das crianças e adolescentes.

Professores têm sido considerados atores importantes nesse processo. Para além do fato de eles serem os responsáveis mais diretos por um dos direitos fundamentais - o direito à educação -, a própria essência de sua atividade coloca-os em contato direto e continuado com crianças e adolescentes, o que constitui uma situação privilegiada para que conheçam as demandas de seus alunos, assim como para a detecção precoce das situações de violação do direito. Se por um lado não se pode exigir dos professores que se tornem os responsáveis pelos serviços de atenção à criança e ao adolescente vítimas de violência e exploração sexual, dadas as especificidades dessa tarefa, por outro é preciso reconhecer que eles devem ser capacitados a reconhecer os indícios dessas violações, e, sobretudo, conhecer os primeiros passos que permitem acionar a rede de serviços que poderá prestar atendimento às crianças e aos adolescentes que eventualmente deles necessitem.

O programa de capacitação ora proposto se insere nesse espaço: trata-se de desenvolver um conjunto de atividades por intermédio das quais seja possível aos professores da rede pública: (a) conhecer o modelo legal, como forma de inserir direitos específicos

2 A justificativa e o objetivo apresentados à SECAD e aqui reproduzidos foram elaborados conjuntamente com a Prof ${ }^{\mathrm{a}}$. Hebe S. Gonçalves (IP/UFRJ). 
na grade de direitos à proteção integral; (b) identificar sinais de violência e de exploração sexual, seja para identificar as violações de direito onde elas ocorram, seja para orientar as crianças e adolescentes a se protegerem dessas formas de violência; $e$ (c) oferecer instrumentos para o encaminhamento dos casos, nas situações em que esse encaminhamento seja necessário, articulando-se à rede de proteção de direitos.

O projeto tem como principal objetivo promover, no âmbito escolar, a defesa dos direitos de crianças e adolescentes em situações de violência física, psicológica, negligência, abandono, abuso sexual, exploração do trabalho infantil, exploração sexual comercial e tráfico para esses fins, em uma perspectiva preventiva, através da(o):

- formação de profissionais de educação para a identificação de evidências de situações de violência; e enfrentamento no âmbito educacional, em uma perspectiva preventiva;

- sensibilização e conscientização da comunidade escolar sobre os prejuízos causados pelas diversas formas de violência no desenvolvimento biofísico-psíquico-social das crianças, adolescentes e à familia como um todo; - estreitamento das relações e integração dos sistemas de ensino ao fluxo de notificação e encaminhamento junto à Rede de Defesa, Responsabilização e Proteção à criança $e$ adolescente.

\section{Conteúdo programático, metodologia e operacionalização}

O programa de capacitação totaliza 32 horas/aula, realizadas semanalmente com encontros temáticos de 4 horas/aula, conforme descrito a seguir:
1. Violência e Direitos Humanos; 2. ECA - de menor a criança; 3. Exploração do Trabalho Infantil; 4. Violência Doméstica; 5. Identificando situações de violência doméstica; 6. Exploração Sexual e Comercial; 7. ECA e violação de direitos: desdobramentos jurídicos; 8. Rede de Proteção Social - Mesa Redonda de encerramento - vários coordenadores.

A concepção metodológica adotada para a realização dos encontros foi a de que estes acontecessem de modo descentralizado, visando garantir o maior número de participantes em cada um dos municípios.

Os docentes responsáveis pelos diferentes temas são em sua maioria absoluta vinculados à UFRJ, com trajetória de pesquisa e consultoria sobre as referidas áreas temáticas. A interdisciplinaridade para a escolha dos mesmos também se constituiu em um critério metodológico. Os docentes que participam do projeto estão vinculados às seguintes unidades da UFRJ: Escola de Serviço Social, Instituto de Psicologia, Faculdade de Direito, Faculdade de Educação, Instituto de Economia e o Instituto de Pediatria.

Para o último encontro, a previsão de realização de uma mesa redonda teve por objetivo propiciar um espaço de interlocução entre as diferentes entidades municipais que trabalham na defesa e garantia de direitos de crianças e adolescentes. Para este último encontro, o público não fica restrito aos inscritos formais, realizando-se uma ampla divulgação. Cada município escolhe para a composição da mesa os interlocutores que julga essenciais para o fortalecimento desta rede de proteção em âmbito local. Os municípios têm freqüentemente convidado para compor a mesa representantes: da própria Secretaria de Educação, da Secretaria de Assistência Social, do Conselho Municipal da Criança e do Adolescente, do Conselho Municipal da Assistência e dos Conselhos Tutelares.

Para alcançar os objetivos traçados, foram adotadas várias estratégias. No que se 
refere ao alinhamento conceitual e definição dos instrumentos pedagógicos (utilização de vídeos, artigos de apoio, poesias, etc.), foram realizadas reuniões entre os docentes que integram $\mathrm{o}$ projeto. No que se refere à possibilidade de um maior enraizamento do projeto nos municípios, a coordenação pedagógica teve por perspectiva estreitar os vínculos com a coordenação do Programa Escola Aberta, participando de reuniões com os coordenadores dos demais projetos em curso no estado, bem como das reuniões do Comitê Metropolitano ${ }^{3}$. Ainda nesta direção foram realizadas reuniões com os interlocutores e gestores em seus próprios municípios.

É importante destacar que o êxito de realização desta proposta tem como suporte fundamental o empenho dos interlocutores municipais. São eles os responsáveis pela divulgação do curso no município, mobilização dos cursistas ${ }^{4}$, realização das inscrições, gestões junto aos diretores de escola para liberação dos cursistas de suas atividades de sala de aula, viabilização de um local adequado à realização dos encontros e identificação e convite aos representantes que participam da mesa de encerramento.

Assim, o projeto Escola que Protege, ao qualificar a compreensão $e$ análise dos professores da rede pública sobre as diferentes formas de violação de direitos de nossas crianças e adolescentes e propiciar um espaço de interlocução com as entidades municipais que atuam diretamente com o fenômeno, tem por objetivo central fortalecer a idéia de que a escola é um dos equipamentos fundamentais da rede de proteção social.
Considerações acerca da rede de proteção social

O debate sobre proteção social não é novo. Para este artigo serão utilizadas as diretrizes inscritas na Política Nacional de Assistência - PNAS, aprovada em 2004, como balizadoras desta discussão.

O inciso I do artigo 203 da Constituição prevê que a família demanda uma gama de serviços de proteção social para que possa desempenhar suas funções protetivas: "A assistência social será prestada a quem dela necessitar, independentemente de contribuição à seguridade social, e tem por objetivos: I - a proteção à família, à maternidade, à infância, à adolescência e à velhice".

De acordo com a PNAS (2004, p. 25), a proteção social se expressa através das "formas institucionalizadas que as sociedades constituem para proteger parte ou conjunto de seus membros".

Este destaque mostra-se relevante, pois nossa trajetória histórica de análise $e$ intervenção junto às famílias empobrecidas tem sido a de individualização e culpabilização pelos problemas, deixando de lado a problematização sobre as condições objetivas existentes que ofereçam o suporte necessário para o enfrentamento das dificuldades por elas vivenciadas. Assim é que, enfatizar a dimensão da proteção social como uma das responsabilidades do Estado, significa o reconhecimento da responsabilidade coletiva e diferenciada na reprodução desta instituição, distanciando-se de uma perspectiva de favorecimento por uma condição de incapacidade.

\footnotetext{
3 O Comitê Metropolitano é constituído pela coordenação do programa Escola Aberta e por representantes das Secretarias Municipais qualificados como interlocutores.

4 Termo utilizado para definir aqueles que se inscrevem no curso.
} 
Como afirma Oliveira (2003, p. 21): "[...] a proteção social pública não é assistencialismo".

Neste sentido, não é demais ressaltar a proteção social como dever do Estado e direito dos cidadãos, bem como o fato de que esta dimensão não se restringe ao campo da assistência.

Desde 2005 vive-se em todo o país no âmbito da assistência à implementação do Sistema Único de Assistência Social - SUAS.

O SUAS se constitui em um sistema integrado, descentralizado e participativo, compreendendo os serviços sócio-assistenciais de órgãos públicos e entidades não-governamentais, tendo a família como foco da atenção e o território como base da organização.

O SUAS 5 está organizado por níveis de proteção social: básica e especial.

a) Proteção social básica

- Objetiva promover a atenção às situações de vulnerabilidade;

- Objetiva prevenir situações de potencial risco social - violação de direitos;

- Objetiva o fortalecimento de vínculos familiares e comunitários;

- Objetiva promover o desenvolvimento de potencialidades - protagonismo;

- Objetiva processar a inclusão de grupos em situação de risco social;

- A provisão dos benefícios (BPC e os benefícios eventuais);

- Desenvolver ações que envolvam vários setores.

Este nível de proteção deve ser realizado pelos Centros de Referência da Assistência Social - CRAS - através da oferta de:

. serviços de fortalecimento dos vínculos familiares;
. serviços e processos de fortalecimento da convivência comunitária e pertencimento às redes microterritoriais;

. serviços de referência para escuta, informação, apoio psicossocial, defesa, encaminhamentos monitorados;

. inclusão nos serviços das demais políticas públicas;

- desenvolvimento de competências e oportunidades de inclusão no mundo do trabalho e renda.

Os CRAS, de acordo com a PNAS, devem compreender as seguintes modalidades de programas:

- Programa de Atenção Integral à Família;

- Programa de inclusão produtiva e projetos de enfrentamento à pobreza;

- Centros de convivência de idosos;

- Serviços para crianças de 0 a 6 anos;

- Serviços socioeducativos para crianças, adolescentes e jovens, na faixa de 6 a 24 anos;

- Programas de incentivo ao protagonismo juvenil;

- Centros de informação e educação para o trabalho, para jovens e adultos.

\section{b) Proteção social especial}

- Destina-se a situações mais graves de exclusão social e de violação de direitos (abandono, maus tratos, cumprimento de medidas socioeducativas, trabalho infantil, etc);

- Visam à reestruturação do grupo familiar e das redes de suporte social, bem como à reestruturação de serviços de abrigamento de indiví-

\footnotetext{
5 As formulações aqui expressas sobre os níveis de proteção do SUAS foram extraídas de VASCONCELOS e MORGADO (2005), aonde são mais detalhadamente analisadas.
} 
duos que não contam mais com a família, em instituições não totais ou segregadoras;

- Têm estreita interface com o sistema de Justiça.

A proteção social especial se divide em duas:

I) média complexidade: operada através do Centro de Referência Especializado de Assistência Social - CREAS - e demais programas e serviços especializados, destina-se a famílias $e$ indivíduos com seus direitos violados, mas cujos vínculos familiar e comunitário não foram rompidos. Neste sentido, requerem maior "estruturação técnico-operacional e atenção especializada e individualizada, e/ou de acompanhamento sistemático e monitorado" através de (PNAS, 2004, p. 31):

- serviços de orientação e apoio sociofamiliar;

- plantão social, abordagem de rua, cuidado no domicílio;

- serviços de habilitação e reabilitação para portadores de deficiência;

- medidas socioeducativas em meio aberto.

II) alta complexidade: famílias e indivíduos sem referência ou sob ameaça, necessitando ser retirados do núcleo familiar e/ou comunitário, e garantindo proteção integral, como moradia, alimentação e trabalho protegido; serviços de casa lar, república, casa de passagem, albergue, família substituta ou acolhedora, medidas socioeducativas restritivas e privadoras de liberdade, e o trabalho protegido.

Destacar, brevemente, estes marcos para a implementação da política de assistência como política pública e da lógica do SUAS deixa evidente o quanto esta perspectiva é recente em nosso país. Por esta razão, o atual momento impõe enormes desafios a sua consolidação na direção de garantia de direitos e enfrentamento das desigualdades sociais.

Nas palavras de Souza (2006, p. 87):

A assistência social, entendida como política pública, direito do cidadão e dever do Estado, se está garantida sob o ponto de vista legal, esbarra nos tradicionais mecanismos sob os quais a prática da assistência, entendida como ajuda, caridade, benesse, favor, historicamente foi construída em nosso país.

De acordo com a Norma Operacional Básica da Assistência, aprovada em 2005, os Centros de Referência da Assistência - CRAS - têm um papel central na realização do mapeamento e na articulação da rede de serviços socioassistenciais. Identifica-se nesta proposta um veio fecundo para o desempenho dos CRAS na construção e consolidação de uma rede de proteção social que transcenda o campo da assistência, tendo por referência principal as demandas municipais.

Nesta direção, cabe pensar como a escola como um equipamento também público, tendo por objetivo central a formação de seus alunos, integra/constrói/consolida esta rede de proteção social. Os alunos que estão matriculados nas escolas públicas são, em geral, os mesmos que demandam serviços à assistência. O Programa Bolsa-Família pode ser usado como exemplo. Através das condicionalidades ${ }^{6}$, a educação $e$

\footnotetext{
$6 \quad$ A existência de condicionalidades, para a permanência no programa tem provocado extensos debates, pois podem ser analisados como propiciadores de acesso a outros direitos (educação e saúde) ou punitivos, quando o próprio poder público não disponibiliza estes mesmos serviços em quantidade e qualidade adequadas às demandas da população.
} 
a saúde atestam, informando ao sistema que gerencia o programa as crianças que estão com a vacinação em dia, aquelas que não atingiram $85 \%$ de freqüência escolar e as gestantes que estão fazendo o pré-natal. Ao ter por base estes critérios para a permanência dos beneficiários no programa, estas três áreas - educação, saúde e assistência - são compelidas a trabalhar de modo conjunto naquilo que se intitula "a gestão das condicionalidades". Face a nossa herança histórica de realização de políticas sociais de forma fragmentada, este trabalho intersetorial, fundamental para a qualidade da ação, mesmo que não houvesse as condicionalidades e para além do Programa Bolsa-Família, enfrenta ainda inúmeros problemas.

Nesta perspectiva, propomos que os elementos abaixo descritos sejam considerados como pressupostos fundamentais para a construção de uma rede de proteção social:

- entendê-la como um processo permanente de mobilização;

\section{REFERÊNCIAS}

BRASIL. Estatuto da Criança e do Adolescente. Lei 8.069 de 13 de julho de 1990.

Política Nacional de Assistência Social. Brasília - DF. Ministério do Desenvolvimento Social e Combate à Fome, 2004.

Norma Operacional Básica - NOB/SUAS: construindo as bases para a implantação do Sistema Único de Assistência Social. Brasília-DF. Ministério do Desenvolvimento Social e Combate à Fome, 2005.

COUTO, B. O direito a assistência social na sociedade brasileira: uma questão possível? São Paulo: Cortez, 2004.

BOSCHETI, I. Assistência social no Brasil: um direito entre a originalidade e o conservadorismo. Brasília: UnB, 2003.

FONSECA, A. M. Família e política de renda mínima. São Paulo: Cortez, 2001.

GARCIA, J. Política social e serviço social - contextos distintos, desafios semelhantes. Serviço Social e Sociedade, v. XXVII, n. 86, São Paulo: Cortez, 2006.

LAVINAS, L.; GARCIA, E. Programas sociais de combate à fome. Rio de Janeiro: Ed. UFRJ/IPEA, 2004.
- requer um pacto de cooperação explícita;

- pressupõe a discussão sobre a concepção de proteção social;

- deve contribuir para romper com a fragmentação das políticas sociais;

- deve potencializar a aplicação de recursos (financeiros e humanos);

- deve otimizar o oferecimento de serviços;

- deve favorecer a qualificação do atendimento;

- deve favorecer a ampliação do atendimento;

- deve contribuir para a integração de diferentes segmentos institucionais $e$ organizados da sociedade;

- deve fortalecer os espaços de gestão mais democráticos da sociedade;

- deve fomentar possibilidades de articulação regional.
MARTINS, J. S. O massacre dos inocentes. São Paulo: Hucitec, 1993.

MOURÃO, E.; MORGADO, R. Subsídios analíticos e metodológicos na lógica do SUAS e do Programa de Atendimento Integral à Família - PAIF/Rio de Janeiro. Secretaria de Estado da Família e da Assistência Social, 2005.

OLIVEIRA, M. J. Cultura política e assistência social: uma análise das orientações de gestores estaduais. São Paulo: Cortez, 2003.

PORFÍRIO, M.; FILHO, R. S.; BACKX, S. Assistência social: contextualização e legislação. Rio de Janeiro: Secretaria de Ação Social e Cidadania do Estado do Rio de Janeiro, 2001.

RAICHELIS, R. Esfera pública e Conselhos de Assistência Social. São Paulo: Cortez, [19-?].

SOUZA, F. V. A política de assistência social: começando o debate. In: REZENDE, I.; CAVALCANTI, L. (Orgs.). Serviço social e políticas sociais. Rio de Janeiro: Editora UFRJ, 2006.

SPOSATI, A. et. al. Assistência na trajetória das políticas sociais brasileiras. São Paulo: Cortez,1985. 
SPOSATI, A. A menina LOAS: um processo de construção da Assistência Social. São Paulo: Cortez, 2004.

Especificidade e intersetorialidade da política de assistência social. Serviço Social e Sociedade, v. XXV, n. 77, São Paulo: Cortez, 2004.

. Contribuição para a construção do Sistema Único de Assistência Social - SUAS. Serviço Social e Sociedade, n. 78, São Paulo: Cortez, 2004.
TORRES, I. C. As primeiras damas e a assistência social: relações de gênero e poder. São Paulo: Cortez, 2002.

YAZBEK, M. C. Classes subalternas e assistência social. São Paulo: Cortez, 1993.

As ambigüidades da assistência social brasileira após dez anos de LOAS. Serviço Social e Sociedade, v. XXV, n.77, São Paulo: Cortez, 2004.

Texto recebido em 19 set. 2007

Texto aprovado em 22 jan. 2008 